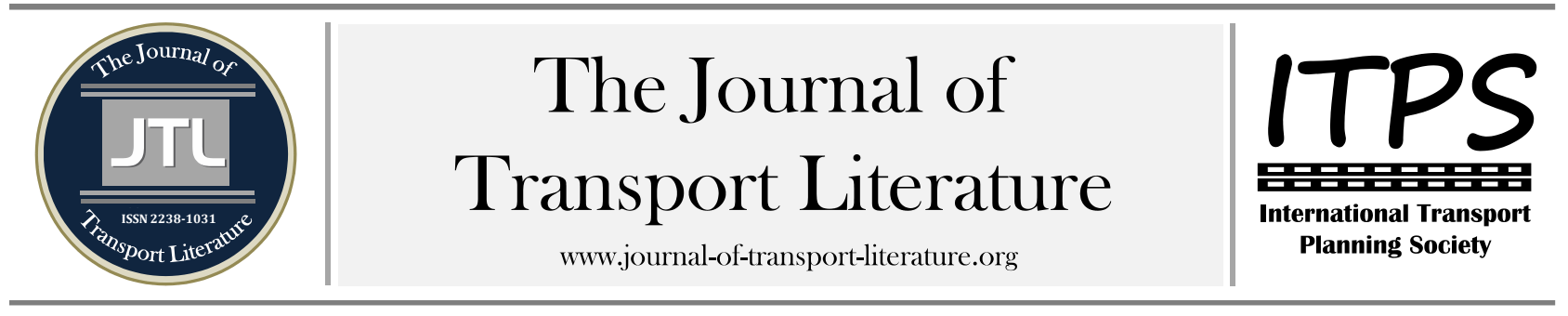

\title{
Análise da ocupação veicular para a inserção de beneficiários no transporte coletivo urbano
}

Sérgio Silvestrini Ferreira; Heloisa Maria Barbosa+

Universidade Federal de Minas Gerais, Belo Horizonte, Brasil

\section{Article Info}

Palavras-chave:

tarifa social

taxa de ocupação

transporte público

Submitted 13 Apr 2015;

received in revised form 14 Jul 2015

accepted 14 Jul 2015.

Licensed under

Creative Commons

CC-BY 3.0 BR.

\section{Resumo}

Este trabalho apresenta um método capaz de acompanhar e avaliar as taxas de ocupação críticas nos ônibus urbanos nos trechos mais carregados durante a operação. 0 objetivo é detectar períodos do dia com taxas inferiores às máximas estabelecidas nos contratos de concessão do serviço, para inclusão de beneficiários sem necessidade do pagamento integral da tarifa. 0 método, baseado em pesquisas de movimentação de passageiros e no tratamento e análise estatística dos dados do Sistema de Bilhetagem Eletrônica - SBE, foi aplicado para o caso de Belo Horizonte-MG. Foi formulado um parâmetro de qualidade, Índice de Conforto Desejável para determinar a capacidade ociosa da frota em operação e quantificar os beneficiários com descontos na tarifa por períodos determinados. A avaliação econômica mostra que em Belo Horizonte, no entrepico, podem ser inseridos mais de 100.000 beneficiários, aproximadamente o total de desempregados na cidade. 0 estudo demonstrou que investimentos em tecnologias de transportes permitem implantar políticas de inclusão econômica e tornar o ônibus acessível às categorias excluídas, sem provocar alterações no nível de qualidade e desequilíbrios financeiros ao sistema.

+ Corresponding author. UFMG - Escola de Engenharia - Bloco 1 - sala 3611. Av. Antônio Carlos, 6627 - 30123-970 - Belo Horizonte - MG - Brasil.

E-mail address: helobarb@etg.ufmg.br

\section{Introdução}

A exclusão econômica é definida por Vasconcellos (2005) em função da renda média dos trabalhadores brasileiros que é baixa e muitas pessoas não têm como pagar as passagens do transporte coletivo. 0 custo das gratuidades e descontos nas tarifas é incluído no cálculo do serviço e pago pelos demais passageiros que, em sua maioria, têm renda baixa (Vasconcellos, 2005). O Ministério das Cidades (2004) mostra o peso considerável das gratuidades nas tarifas: 22,70\% em Belém, Campo Grande 29\%, Porto Velho 25\%, e São Paulo de 10 a 12\%. Embora o transporte público deva ser tratado como um bem primário ou um serviço público essencial para garantir a mobilidade urbana (Pires, 2008), nas grandes cidades, cerca de 35 milhões de brasileiros não conseguem utilizar o transporte público de forma regular por falta de recursos financeiros, ficando limitados ao entorno de suas moradias (Carvalho et al., 2010). Para Nunes (2010) este fenômeno é mais frequente para quem não possui qualquer tipo de subsídio ou isenção, por exemplo, as pessoas fora do mercado de trabalho.

A adequação da oferta de transporte público à variação temporal da demanda impõe uma relativa ociosidade de parcela da frota no entrepico. Logo, nas grandes cidades, ocorre a seguinte situação antagônica: superlotação e demanda reprimida nos picos e, ônibus vazios no fora pico. 0 que pensam os excluídos econômicos, vendo esses ônibus circulando vazios? Não seria socialmente correto promover a inclusão no transporte destas pessoas nesses horários? Assim, foram levantadas três hipóteses: (i) É possível inserir novos beneficiários mantendo o equilíbrio econômico-financeiro do sistema? (ii) É provável que existam períodos em que a ocupação dos ônibus esteja abaixo da taxa máxima acordada nos contratos de concessão; (iii) Se existe ociosidade e os custos operacionais são cobertos pela receita dos horários de maior demanda, presume-se que usuários embarcados nesses horários não terão, teoricamente, a necessidade de pagar integralmente a tarifa.

Este artigo apresenta um método para medir e avaliar as taxas de ocupação nos ônibus, por viagem, nos trechos mais carregados durante a operação diária, estabelecendo critérios para verificar a capacidade ociosa por tipo de serviço, e promover a inserção de beneficiários sem impactar o equilíbrio econômico-financeiro do sistema e sem prejudicar a qualidade do serviço. Propõe-se, então, um parâmetro de gestão operacional, Índice de Conforto Desejável - ICD para determinar o número desses beneficiários. 0 procedimento tem um importante aspecto social, pois torna o ônibus acessível às categorias até então excluídas, sem danos ao sistema.

A seção 1 deste artigo descreve aspectos da tarifação e o uso das informações dos Sistemas de Bilhetagem Eletrônica - SBE sendo que a aplicação aqui proposta não consta da bibliografia consultada. A seção 2 detalha o método de análise da ocupação e a formulação do ICD. A aplicação do método para o caso de Belo Horizonte e os resultados são tratados nas seções 3 e 4, respectivamente. As conclusões trazem resultados, contribuições, requisitos e aplicações do método.

\section{Aspectos da tarifação e da bilhetagem no transporte público}

Na maioria das cidades brasileiras, o setor de transporte urbano adota uma regulação tarifária pelo custo de serviço, geralmente, com poucas ou sem regras preestabelecidas, o que gera ao setor interferências políticas e empresariais que comprometem os níveis de serviços e o equilíbrio econômico-financeiro dos contratos (Couto, 2011). Desde 2008, Belo Horizonte substituiu o modelo de remuneração baseado nos custos operacionais, com planilha de atualização de preços e revisão de custos e tarifas, por um modelo com reajuste baseado em índices públicos medidos por institutos de pesquisa, e DOI: http://dx.doi.org/10.1590/ 2238-1031.jtl.v10n2a8 
remuneração pautada na receita tarifária acrescida de receitas alternativas (Couto, 2011). 0 modelo permitiu incluir, no contrato de concessão, cláusulas referentes a requisitos mínimos de qualidade dos serviços, e a flexibilização no planejamento e na programação operacional, antes atribuição única do órgão gestor.

0 advento dos SBE, decisivo na contenção da evasão da receita e no consequente aumento da arrecadação (ANTP, 2012), propiciou o controle mais eficiente da gratuidade no transporte coletivo, e gerou um efeito pouco percebido pelo público, mas importante, que é o controle da oferta de transporte, através das inúmeras informações sobre as viagens realizadas, frota em serviço, indicadores de ociosidade, entre outros. A bibliografia sobre o uso de dados do SBE contém um maior número de pesquisas relativas à estimativa de matrizes de Origem-Destino - 0/D. Zhao (2004) criou metodologia para inferir o destino de um passageiro em um sistema de trilhos associando os dados do SBE, do sistema de Localização Automática do Veículo - AVL e de rede em SIG - Sistema de Informação Geográfica. Com dados de múltiplos sistemas de coleta automática Cui (2006) elaborou metodologia para estimar matriz O/D para ônibus, em sistema com controle apenas de entrada. Trépanier et al. (2008) compararam dados do SBE com pesquisas O/D, sendo o primeiro exercício de comparação desses dois conjuntos de dados. Farzin (2008) criou metodologia para obter uma matriz O/D para a cidade de São Paulo a partir de três fontes primárias de dados: transmissões do sistema AVL, localização geográfica dos pontos de parada das linhas em análise e dados do SBE. Guerra et al. (2014) criaram uma rede em SIG e trataram dados do SBE para determinar a matriz semente e estimar a matriz O/D final do transporte por ônibus de Maceió. Abordagens distintas foram relatadas por: Cham (2006) que propôs um guia prático para órgãos gestores avaliar a confiabilidade do serviço de transporte e as causas da possível falta de confiabilidade; Mojica (2008) analisou mudanças no padrão de viagens de uma amostra de passageiros ferroviários através de registros nos cartões eletrônicos para mensurar a troca modal dos trilhos para ônibus; e Lathia et al. (2013) identificaram diferenças no comportamento de passageiros segundo o padrão de viagens observado para criar serviços de informação de viagens voltados para as necessidades e características individuais de cada usuário. Devido ao potencial das informações geradas, o SBE mostra-se eficaz para avaliar a ocupação do ônibus, apurar e monitorar a operação em termos de conforto, para a inclusão de beneficiários usando a ociosidade medida por indicadores como o Índice de Conforto Desejável, ICD, introduzido neste artigo, enfoque não encontrado na bibliografia consultada.

\section{Método proposto}

2.1 Embasamento legal: além da análise das regulamentações vigentes foram avaliadas as cláusulas contratuais que estabelecem os níveis mínimos de qualidade, referentes ao índice de conforto e os intervalos máximos de operação por faixa horária. A etapa é prioritária, pois se não houver regras que garantam uma frequência mínima para as viagens em todos os períodos do dia, mesmo nas faixas horárias de baixa ocupação, a eficácia do método estará comprometida.

2.2 Embasamento tecnológico: foram utilizadas informações disponibilizadas pelo órgão gestor para avaliações operacionais e tratamento estatístico a partir de três bases de dados primários: (i) pesquisas de movimentação de passageiros realizadas em campo pela Empresa de Transportes e Trânsito de Belo Horizonte S/A - BHTRANS, com informações de índice de renovação ou rotatividade, gratuidades e transbordos; (ii) dados do SBE sobre as viagens, tipos de serviço, passageiros, tarifas, integrações, horários, quilometragem; (iii) dados dos ônibus urbanos, como dimensões físicas, número de assentos disponíveis e área útil do corredor. Foi usado o software BH03 da BHTRANS que possibilita checar várias informações e acompanhar o desempenho da operação. Sua interface online permite a inserção dos cálculos nos servidores, interagindo com os bancos do SBE e de armazenamento de dados de movimentação de passageiros.

2.3 Determinação da ocupação do ônibus: os dados de pesquisas de movimentação de passageiros processados no BH03 fornecem os seguintes índices: Índice de Rotatividade (irot) é a relação entre o total de passageiros transportados na viagem e a ocupação máxima em seu trecho crítico. A ocupação no trecho crítico (Otc) é a máxima ocupação ocorrida ao longo da viagem em seu trecho crítico (Eq. 1):

$$
O_{t c}=\frac{u_{S B E}\left(i_{u n c}-1\right)}{i_{\text {rot }}}
$$

em que: iunc = índice de usuários não catracados (Equação 2); uSBE = total de usuários contabilizados pelo SBE ao passar pela catraca, usando cartão eletrônico ou pagando passagem em dinheiro.

$$
i_{\text {unc }}=i_{\text {grat }}+i_{\text {transb }}
$$

Índice de Gratuidade (igrat) é a relação entre passageiros transportados na viagem e a quantidade de usuários que entram e saem pela porta dianteira do ônibus e não passam pela catraca, geralmente beneficiários de gratuidade. Índice de Transbordo (itransb) é a relação entre passageiros transportados na viagem e a quantidade de usuários que entram pelas portas de saída e não passam pela catraca, geralmente nas áreas pagas das estações fechadas de integração. Capacidade Nominal do veículo $(\mathrm{CN})$ é o número máximo de passageiros transportados simultaneamente em um veículo padrão, em condições limites de conforto, expressa pela Equação 3, considerando o número total de assentos e a taxa de ocupação máxima permitida em função da área útil do corredor:

$$
C N=\text { Passag. sentados + (área útil x taxa de ocupação máxima) }
$$

Índice de Ocupação de Passageiros no trecho crítico (Iopc) é a quantidade máxima de passageiros transportados ao mesmo tempo em um veículo, no trecho crítico. É usado na apuração e monitoramento das condições operacionais da linha em termos de conforto, aferindo a lotação nesse trecho (Equação 4). Considerando as taxas máximas de ocupação admissíveis, são consideradas viagens não lotadas aquelas com Iopc inferior a 1,0, e superlotadas com Iopc maior que 1,0.

$$
I_{\text {opc }}=\frac{O_{t c}}{C N}
$$

\subsection{Formulação do indicador de qualidade do nível de conforto desejável}

A taxa de ociosidade, em termos percentuais, corresponde a lugares disponíveis e não ocupados em uma viagem não lotada. $\mathrm{O}$ fator de confortabilidade - fc é importante para manter o conforto acima do nível estabelecido em contrato, evitando ultrapassá-lo durante as sazonalidades diárias. 0 fc é estabelecido em função do desvio padrão da média aparada do Iopc das oito faixas horárias que compõem o período do entrepico, e ponderada pelo percentual de viagens por tipo de serviço. A demanda máxima no trecho crítico somada à capacidade ociosa alcança a situação ótima de eficiência econômica $($ Iopc $=1,0)$. 0 Índice de Conforto Desejável - ICD, indicador de qualidade foi formulado para definir a ocupação desejável em termos de eficiência econômica, em função do Iopc máximo permitido (Iopc $=1,0$ ) e do fc, conforme Equação 5:

ITPS, Manaus, Brazil. ISSN 2238-1031. 


$$
I C D=1,0-f_{c}
$$

O ICD subsidiará o cálculo do quantitativo de novos beneficiários que poderão utilizar o sistema com desconto total ou parcial na tarifa, sem negligenciar o nível de conforto estabelecido, e sem ultrapassar as taxas máximas de ocupação. Calcula-se então a demanda desejável, aplicando este índice à capacidade média nominal da frota. 0 acréscimo de passageiros por viagem será a diferença entre a demanda desejável calculada e a demanda média real apurada. Multiplicando este valor pelo número de viagens com Iopc abaixo de 1,0, tem-se o acréscimo total de passageiros, correspondente ao número de lugares considerados ociosos para o período estudado (entrepico). Divide-se o total de lugares ociosos por dois, pois o usuário vai e volta, ou seja, um usuário corresponde a dois passageiros.

\section{Aplicação do método}

O transporte convencional por ônibus de Belo Horizonte, em números aproximados, transporta 1,5 milhão de passageiros (dia útil) por 300 linhas e frota de 3.000 veículos, realizando 760.000 viagens/mês, com produção quilométrica mensal de 16 milhões de km. O SBE opera 1.880.000 cartões eletrônicos BHBUS, sendo 1.711 .000 cartões de pagamento, 153.000 cartões Benefício e o restante de cartões operacionais. Do total de passageiros catracados, $60 \%$ usam cartão BHBUS (BHTRANS/GECET, 2012). Nesta aplicação foram usados dados operacionais de dias úteis de outubro/2012, mês mais próximo da média do sistema (cerca de 653.000 viagens). Todavia, o método pode ser aplicado em qualquer mês e ano, e deve ser monitorado e avaliado mês a mês pelo órgão gestor. Este artigo mostra a análise da ocupação geral para 653.785 viagens de todas as linhas do sistema. A análise dos indicadores de lotação segue a metodologia descrita. Os valores da Tabela 1 foram obtidos com o BH03, considerando os serviços mais representativos: diametral, circular, radial, troncal, perimetral, semi-expresso, e alimentador.

Tabela 1 - Indicadores de lotação geral

\begin{tabular}{|c|c|c|c|c|c|c|c|c|c|c|c|}
\hline Faixa horária & $\begin{array}{c}\text { Viagens } \\
\text { realiza } \\
\quad \text { das }\end{array}$ & $\begin{array}{l}\text { Demanda } \\
\text { médial } \\
\text { viagem } \\
\text { trecho } \\
\text { crítico }\end{array}$ & $\begin{array}{l}\text { Capacidade } \\
\text { médial } \\
\text { viagem }\end{array}$ & $\begin{array}{c}\text { Média } \\
\text { de } \\
\text { passag. } \\
\text { sentados }\end{array}$ & $\begin{array}{c}\text { Média } \\
\text { de } \\
\text { área } \\
\text { útil }\end{array}$ & $\begin{array}{c}\text { Média } \\
\text { de rotati } \\
\text { vidade }\end{array}$ & $\begin{array}{c}\text { Média } \\
\text { de } \\
\text { gratui } \\
\text { dade }\end{array}$ & $\begin{array}{l}\text { Média } \\
\text { de } \\
\text { trans } \\
\text { bordo }\end{array}$ & $\begin{array}{l}\text { Viagens } \\
\text { lotadas }\end{array}$ & $\begin{array}{c}\text { Viagens } \\
\text { com } \\
I_{\text {opc }}<1\end{array}$ & $\begin{array}{c}I_{o p c} \\
\text { médio } \\
\text { por } \\
\text { viagem }\end{array}$ \\
\hline $00: 00-00: 59$ & 2.947 & 9,73 & 37,39 & 37,39 & 6,23 & 1,57 & 1,07 & 1,12 & 135 & 2.812 & 0,26 \\
\hline $01: 00-01: 59$ & 1.865 & 8,17 & 37,43 & 37,43 & 6,36 & 1,59 & 1,08 & 1,14 & 89 & 1.776 & 0,22 \\
\hline $02: 00-02: 59$ & 1.672 & 5,30 & 37,38 & 37,38 & 6,36 & 1,57 & 1,08 & 1,18 & 53 & 1.619 & 0,14 \\
\hline $03: 00-03: 59$ & 1.705 & 4,93 & 37,37 & 37,37 & 6,34 & 1,62 & 1,07 & 1,15 & 36 & 1.669 & 0,13 \\
\hline $04: 00-04: 59$ & 9.593 & 18,12 & 55,82 & 37,37 & 6,15 & 1,55 & 1,08 & 1,23 & 422 & 9.171 & 0,32 \\
\hline $05: 00-05: 59$ & 32.239 & 43,54 & 67,28 & 37,46 & 6,16 & 1,51 & 1,07 & 1,15 & 5.068 & 27.171 & 0,65 \\
\hline $06: 00-06: 59$ & 55.600 & 55,14 & 67,85 & 37,30 & 6,18 & 1,50 & 1,07 & 1,18 & 13.882 & 41.718 & 0,81 \\
\hline $07: 00-07: 59$ & 44.414 & 50,12 & 67,58 & 37,25 & 6,15 & 1,51 & 1,09 & 1,38 & 7.918 & 36.496 & 0,74 \\
\hline $08: 00-08: 59$ & 34.286 & 41,66 & 56,46 & 37,27 & 6,14 & 1,58 & 1,14 & 1,22 & 6.555 & 27.731 & 0,74 \\
\hline $09: 00-09: 59$ & 31.911 & 33,60 & 56,56 & 37,27 & 6,13 & 1,71 & 1,19 & 1,16 & 2.492 & 29.419 & 0,59 \\
\hline $10: 00-10: 59$ & 30.252 & 32,73 & 56,49 & 37,25 & 6,11 & 1,81 & 1,18 & 1,12 & 2.020 & 28.232 & 0,58 \\
\hline $11: 00-11: 59$ & 35.576 & 35,27 & 56,47 & 37,29 & 6,13 & 1,82 & 1,15 & 1,11 & 2.986 & 32.590 & 0,62 \\
\hline $12: 00-12: 59$ & 37.619 & 36,38 & 56,44 & 37,28 & 6,14 & 1,80 & 1,14 & 1,11 & 3.618 & 34.001 & 0,64 \\
\hline $13: 00-13: 59$ & 34.846 & 34,10 & 56,50 & 37,28 & 6,14 & 1,85 & 1,17 & 1,12 & 2.614 & 32.232 & 0,60 \\
\hline $14: 00-14: 59$ & 34.215 & 35,07 & 55,75 & 37,29 & 6,15 & 1,83 & 1,18 & 1,11 & 3.132 & 31.083 & 0,63 \\
\hline $15: 00-15: 59$ & 34.020 & 42,32 & 55,69 & 37,26 & 6,14 & 1,74 & 1,16 & 1,12 & 7.584 & 26.436 & 0,76 \\
\hline $16: 00-16: 59$ & 39.888 & 49,76 & 66,89 & 37,23 & 6,15 & 1,70 & 1,12 & 1,15 & 7.690 & 32.198 & 0,74 \\
\hline $17: 00-17: 59$ & 44.396 & 52,08 & 67,04 & 37,25 & 6,16 & 1,67 & 1,10 & 1,15 & 9.087 & 35.309 & 0,78 \\
\hline $18: 00-18: 59$ & 33.687 & 44,19 & 66,58 & 37,17 & 6,13 & 1,64 & 1,10 & 1,22 & 3.792 & 29.895 & 0,66 \\
\hline $19: 00-19: 59$ & 29.847 & 32,06 & 55,53 & 37,17 & 6,12 & 1,63 & 1,11 & 1,31 & 2.359 & 27.488 & 0,58 \\
\hline $20: 00-20: 59$ & 23.614 & 27,45 & 55,50 & 37,19 & 6,10 & 1,64 & 1,11 & 1,29 & 886 & 22.728 & 0,49 \\
\hline $21: 00-21: 59$ & 24.100 & 28,05 & 55,61 & 37,26 & 6,12 & 1,64 & 1,12 & 1,28 & 1.340 & 22.760 & 0,50 \\
\hline $22: 00-22: 59$ & 20.206 & 24,30 & 55,58 & 37,23 & 6,11 & 1,64 & 1,11 & 1,29 & 727 & 19.479 & 0,44 \\
\hline $23: 00-23: 59$ & 15.287 & 12,05 & 55,95 & 37,47 & 6,16 & 1,63 & 1,12 & 1,42 & 96 & 15.191 & 0,22 \\
\hline Total geral & 653.785 & 39,18 & 60,13 & 37,27 & 6,14 & 1,67 & 1,12 & 1,19 & 84.581 & 569.204 & 0,65 \\
\hline
\end{tabular}

Pela Tabela 1,13\% das viagens realizadas têm superlotação e o valor médio do Iopc é 0,65. A capacidade média da frota, considerando as taxas de ocupação variáveis por período, é de 60 passageiros/veículo, e a rotatividade é $67 \%$. 0s números apontam uma taxa média de gratuidade de 12\%, sendo que 19\% dos usuários utilizam as estações de integração e fazem transbordo para concluírem as suas viagens. 0 percentual das viagens lotadas para todo o sistema nas 24 faixas horárias do dia pode ser visualizado na Figura 1, cujas cores das barras representam os períodos assim ordenados: noturno (0:004:59), pico manhã (5:00-7:59), entrepico (8:00-15:59), pico tarde (16:00-18:59) e fora pico (19:00-23:59). Verifica-se na Figura 1 uma redução das viagens lotadas no entrepico, sugerindo redução da demanda neste período. Esta queda fica mais caracterizada ao se considerar a taxa de ocupação menor em relação à taxa dos horários de pico. Verifica-se também no início e final do entrepico (faixas horárias 9 e 16), o comportamento diferente da demanda das demais faixas do período, sugerindo a redução gradativa da demanda entre 08:00 e 09:00, e o crescimento gradativo, de 15:00 às 15:59. As viagens especificadas para o sistema, dias úteis (out/2012) no entrepico (08:00 às 15:59), período adotado neste estudo, apresentam os maiores percentuais em relação às demais faixas horárias (41\% das viagens diárias).

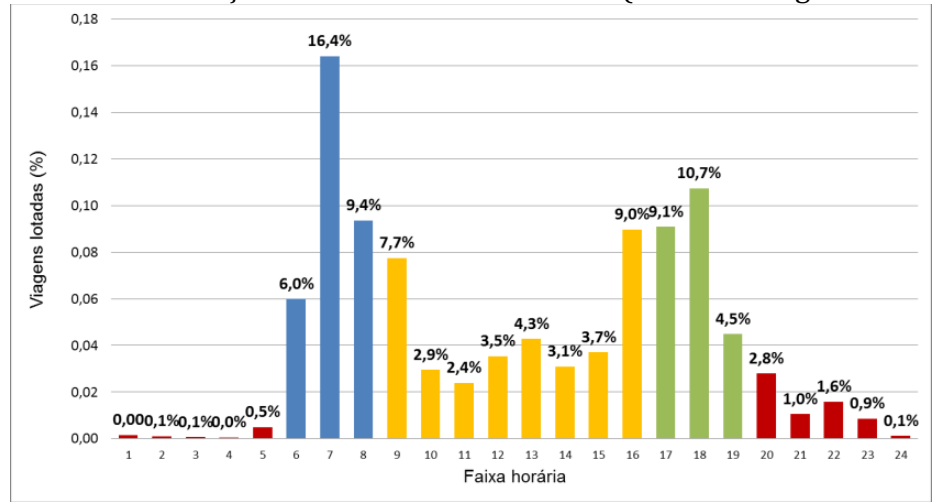

Figura 1 - Viagens lotadas por faixa horária para o todo o sistema 


\section{Análise e resultados}

Para a validação do método foi adotado o Índice de Conforto Desejável, ICD, inferior ao Iopc máximo permitido. 0 ICD é calculado em função do Iopc máximo e do fc. Calcula-se o desvio padrão dos Iopc para cada faixa horária, descartando o maior e o menor valor do Iopc (média aparada), para cada serviço separadamente. A média dos desvios padrão calculados, ponderada pelo número de viagens que cada serviço representa no sistema, fornece o fc. Por exemplo, o serviço diametral que opera $46 \%$ das viagens terá um peso maior do que o circular que opera apenas $5 \%$ das viagens. Expandindo o Iopc, já calculado, para quatro casas decimais, obtiveram-se os resultados da Tabela 2 no entrepico para cada tipo de serviço. A média dos dados gerais do sistema por faixas horárias do entrepico, para todos os serviços, está na Tabela 3.

\begin{tabular}{|c|c|c|c|c|c|c|c|c|c|}
\hline & \multicolumn{2}{|c|}{$\begin{array}{l}\text { Alimentador } \\
\qquad L\end{array}$} & $\begin{array}{c}\text { Circular } \\
\text { CI }\end{array}$ & $\begin{array}{c}\text { Diametral } \\
\text { DI }\end{array}$ & \multicolumn{2}{|c|}{$\begin{array}{l}\text { Perimetral } \\
P E\end{array}$} & $\begin{array}{c}\text { Semi- } \\
\text { expresso } \\
\text { SE }\end{array}$ & $\begin{array}{c}\text { Troncal } \\
\text { TR }\end{array}$ & $\begin{array}{c}\text { Radial } \\
R A\end{array}$ \\
\hline \multirow{2}{*}{\multicolumn{2}{|c|}{$\begin{array}{c}\text { Viagens realizadas } \\
\text { Demanda média/viagem } \\
\text { trecho crítico }\end{array}$}} & 47.775 & 13.805 & 125.458 & \multicolumn{2}{|c|}{10.440} & 35.991 & 26.582 & 4.631 \\
\hline & & 30,92 & 40,69 & 37,04 & \multicolumn{2}{|c|}{29,55} & 40,99 & 41,55 & 37,56 \\
\hline $\begin{array}{l}\text { Capacidade médial } \\
\text { viagem }\end{array}$ & & 56,83 & 57,15 & 56,90 & \multicolumn{2}{|c|}{56,58} & 56,55 & 57,36 & 56,27 \\
\hline Média passageiros & & 37,32 & 37,96 & 37,83 & \multicolumn{2}{|c|}{37,38} & 37,56 & 37,67 & 37,41 \\
\hline Média de área útil $\left(\mathrm{m}^{2}\right)$ & & 6,11 & 6,23 & 6,20 & \multirow{2}{*}{\multicolumn{2}{|c|}{$\begin{array}{l}6,01 \\
1,66\end{array}$}} & 6,26 & 6,27 & \multirow{2}{*}{6,22} \\
\hline Média de rotatividade & & 1,85 & 1,95 & 1,70 & & & 1,76 & 1,88 & \\
\hline Média de gratuidade & & 1,18 & 1,15 & 1,17 & \multicolumn{2}{|c|}{1,15} & 1,15 & 1,14 & 1,13 \\
\hline Média de transbordo & & 1,43 & 1,00 & 1,00 & \multicolumn{2}{|c|}{1,00} & 1,00 & 1,59 & 1,00 \\
\hline Viagens lotadas $\left(I_{o p c}>1\right)$ & & 4.244 & 2.523 & 11.657 & \multicolumn{2}{|c|}{679} & 5.109 & 5.326 & \multirow{2}{*}{$\begin{array}{c}457 \\
4.174\end{array}$} \\
\hline Viagens não lotadas & & 43.531 & 11.282 & 113.801 & \multicolumn{2}{|c|}{9.761} & 30.882 & 21.256 & \\
\hline$I_{o p c}$ médio & & 0,5440 & 0,7119 & 0,6510 & 0,522 & & 0,7248 & 0,7243 & 0,6676 \\
\hline \multicolumn{10}{|c|}{ Tabela 3 - Dados gerais por faixa horária e para o entrepico } \\
\hline Faixa horária & $\begin{array}{c}08: 00- \\
08: 59\end{array}$ & $\begin{array}{c}09: 00- \\
09: 59\end{array}$ & $\begin{array}{c}10: 00- \\
10: 59 \\
\end{array}$ & $\begin{array}{l}11: 00- \\
11: 59\end{array}$ & $\begin{array}{l}12: 00- \\
12: 59 \\
\end{array}$ & $\begin{array}{c}13: 00- \\
13: 59\end{array}$ & $\begin{array}{c}14: 00- \\
14: 59 \\
\end{array}$ & $\begin{array}{c}15: 00- \\
15: 59 \\
\end{array}$ & $\begin{array}{c}08: 00- \\
15: 59 \\
\end{array}$ \\
\hline Viagens realizadas & 34.286 & 31.911 & 30.252 & 35.576 & 37.619 & 34.846 & 34.215 & 34.020 & 272.725 \\
\hline Passageiros por viagem & 52,41 & 44,54 & 47,41 & 52,31 & 53,65 & 50,55 & 51,67 & 60,26 & 51,6 \\
\hline Rotatividade & 1,58 & 1,71 & 1,81 & 1,82 & 1,8 & 1,85 & 1,83 & 1,74 & 1,77 \\
\hline Gratuidade & 1,14 & 1,19 & 1,18 & 1,15 & 1,14 & 1,17 & 1,18 & 1,16 & 1,16 \\
\hline Transbordo & 1,22 & 1,16 & 1,12 & 1,11 & 1,11 & 1,12 & 1,11 & 1,12 & 1,13 \\
\hline Passageiros sentados & 37,27 & 37,27 & 37,25 & 37,29 & 37,28 & 37,28 & 37,29 & 37,26 & 37,27 \\
\hline Área útil & 6,14 & 6,13 & 6,11 & 6,13 & 6,14 & 6,14 & 6,15 & 6,14 & 6,14 \\
\hline Capac. média por viagem & 56,46 & 56,56 & 56,49 & 56,47 & 56,44 & 56,5 & 55,75 & 55,69 & 56,29 \\
\hline$O_{t c}$ média por viagem & 41,66 & 33,6 & 32,73 & 35,27 & 36,38 & 34,1 & 35,07 & 42,32 & 36,39 \\
\hline Viagens lotadas & 6.555 & 2.492 & 2.020 & 2.986 & 3.618 & 2.614 & 3.132 & 7.584 & 31.001 \\
\hline Viagens não lotadas & 27.731 & 29.419 & 28.232 & 32.590 & 34.001 & 32.232 & 31.083 & 26.436 & 241.724 \\
\hline$I_{\text {opc }}$ médio por viagem & 0,7378 & 0,5941 & 0,5795 & 0,6245 & 0,6445 & 0,6034 & 0,6291 & 0,7600 & 0,6465 \\
\hline
\end{tabular}

Agrupando os valores relativos ao Iopc médio, utilizando a média aparada obteve-se o desvio padrão dos valores do Iopc por tipo de serviço, conforme Tabela 4.0 valor do fc para o sistema foi obtido em função do desvio padrão da média aparada do Iopc das oito faixas horárias que compõem o período do entrepico, e ponderada pelo percentual de viagens por tipo de serviço. A variável "\% viagens" é o percentual de viagens em relação ao total no entrepico. 0 total geral não atinge $100 \%$, pois o estudo não considerou os serviços Vilas e Favelas, Executivo e Retorno Direto, que perfazem 3\% do total de viagens. Um fc igual a 0,0451 significa, na prática, uma tolerância capaz de neutralizar possíveis impactos da sazonalidade diária da demanda, suportando flutuações de até 4,51\% a mais na demanda no trecho crítico, sem exceder os limites dos contratos de concessão, assegurando a consistência do método. A Tabela 5 mostra o ICD calculado e o resultado da aplicação do método, com a determinação do quantitativo de usuários que poderão utilizar o transporte com descontos na tarifa. Aplicando o ICD e os dados da Tabela 3, que apontou a demanda média por viagem de 56,29 passageiros, a demanda desejável será de 53,75 passageiros, correspondendo a uma capacidade ociosa de 17,36 passageiros por viagem. Considerando as viagens não lotadas de 08:00 às 15:59 (241.724 viagens/mês), acrescentando 17,36 passageiros a cada viagem e dividindo por 22 dias, resulta em 209.854 passageiros, total de lugares disponíveis por dia útil. Como a cada dois passageiros tem-se um usuário, são 104.927 pessoas que poderão utilizar o transporte coletivo de Belo Horizonte diariamente, sem a necessidade do pagamento integral da tarifa. A operacionalização do método é concretizada com a emissão de cartões eletrônicos, formatados para que somente em horários e dias pré-estabelecidos pelo órgão gestor essas pessoas possam usufruir do benefício. É necessário que o sistema possua algum dispositivo embarcado, acoplado ao validador, para fiscalizar eletronicamente o uso exclusivo do cartão benefício, desabilitando-o em caso de uso indevido. Sistemas de biometria digital ou facial cumprem essa função de forma automatizada, rápida e eficiente, evitando-se atritos entre o agente de bordo e o usuário. O SBE monitora o uso dos cartões pelo rastreamento de utilização (dia, hora, linha, etc.), e acompanha a operação diária, indispensável para verificar se o nível de ocupação está dentro dos limites planejados, principalmente nos horários com benefícios concedidos.

Tabela 4 - Iopc, desvio padrão médio e fator de confortabilidade no

\begin{tabular}{ccccccccc}
\multicolumn{8}{c}{ entrepico por serviço } \\
\hline $\begin{array}{c}\text { Tipo Serviço / faixa } \\
\text { horária }\end{array}$ & $\boldsymbol{A L}$ & $\boldsymbol{C I}$ & $\boldsymbol{D I}$ & $\boldsymbol{P E}$ & $\boldsymbol{S E}$ & $\boldsymbol{T O}$ & $\boldsymbol{R A}$ & $\boldsymbol{G E R A L}$ \\
\hline $08: 00-08: 59$ & 0,4783 & 0,5893 & 0,5896 & 0,4320 & 0,6346 & 0,6443 & 0,5949 & - \\
$09: 00-09: 59$ & 0,4925 & 0,6428 & 0,5977 & 0,4577 & 0,6622 & 0,6520 & 0,6008 & - \\
$10: 00-10: 59$ & 0,5107 & 0,6432 & 0,6127 & 0,4623 & 0,6920 & 0,6680 & 0,6260 & - \\
$11: 00-11: 59$ & 0,5283 & 0,6533 & 0,6299 & 0,4939 & 0,7002 & 0,6906 & 0,6379 & - \\
$12: 00-12: 59$ & 0,5551 & 0,6618 & 0,6351 & 0,4971 & 0,7227 & 0,6966 & 0,6542 & - \\
$13: 00-13: 59$ & 0,5856 & 0,7214 & 0,6463 & 0,5001 & 0,7239 & 0,7288 & 0,6660 & - \\
$14: 00-14: 59$ & 0,5951 & 0,8495 & 0,7341 & 0,6680 & 0,7863 & 0,8387 & 0,7692 & - \\
$15: 00-15: 59$ & 0,6076 & 0,9363 & 0,7639 & 0,6694 & 0,8771 & 0,8788 & 0,7918 & - \\
\hline Desvio padrão médio & 0,0376 & 0,0740 & 0,0438 & 0,0712 & 0,0382 & 0,0613 & 0,0535 & 0,0542 \\
\hline \% viagens & $18 \%$ & $5 \%$ & $46 \%$ & $4 \%$ & $13 \%$ & $10 \%$ & $2 \%$ & $97 \%$ \\
\hline $\begin{array}{c}\text { Fator de } \\
\text { confortabilidade } \boldsymbol{f}_{\boldsymbol{c}}\end{array}$ & 0,0066 & 0,0037 & 0,0201 & 0,0027 & 0,0050 & 0,0060 & 0,0009 & 0,0451 \\
\hline & & & & & & & &
\end{tabular}

Tabela 5 - Resultado da aplicação do método para o sistema de Belo Horizonte

\begin{tabular}{|c|c|}
\hline Parâmetros & Valores \\
\hline Fator de confortabilidade $-f_{c}$ & 0,0451 \\
\hline$I_{\text {opc }}$ máximo & 1,0 \\
\hline$I C D$ & 0,9549 \\
\hline Capacidade média por viagem (passageiros) & 56,29 \\
\hline Demanda desejável por viagem (passageiros) & 53,75 \\
\hline Demanda média por viagem (passageiros) & 36,39 \\
\hline Acréscimo de passageiros por viagem & 17,36 \\
\hline Viagens mês com $I_{\text {opc }}<1$ & 241.724 \\
\hline Acréscimo de passageiros por mês & 4.197 .083 \\
\hline Acréscimo de passageiros por dia útil & 209.854 \\
\hline Acréscimo de usuários por dia útil & 104.927 \\
\hline
\end{tabular}




\section{Conclusões}

Este estudo apresentou o desenvolvimento de um método, simples e objetivo, para acompanhar as taxas de ocupação nos ônibus em seus trechos críticos durante a operação e promover a inclusão de beneficiários nos horários de menor demanda. O ICD - Índice de Conforto Desejável foi formulado para determinar a ociosidade da frota e quantificar o número de beneficiários que poderão usar o sistema com descontos na tarifa. A adoção do método apresenta os seguintes requisitos: (i) regulamentação do transporte público com cláusulas no contrato de concessão que garantam qualidade em termos de frequência das viagens e taxa de ocupação máxima; (ii) SBE implantado para extração dos dados operacionais, e aplicativos de controle do uso de cartões eletrônicos; (iii) manter atualizadas as pesquisas de movimentação de passageiros.

A avaliação econômica indicou um superávit em cada viagem no período, ratificando a hipótese de inserção de 104.927 passageiros sem custos adicionais, número muito próximo dos desempregados do município (novembro/2012). Este estudo estabeleceu como público alvo os desempregados, pessoas com dificuldade financeira temporária. Contudo, poderia contemplar outra categoria da população conforme interesse do órgão gestor e das politicas públicas do município. Sugerese a concessão de forma gradativa, monitorando diariamente a operação e o estabelecimento de critérios e prazo do benefício pelo órgão gestor.

Programas baseados no Iopc estão em uso na BHTRANS para verificar a lotação, com resultados bem satisfatórios. 0 excesso sistêmico é apresentado aos operadores para a reprogramação dos quadros de horários no pico, por meio do aumento das viagens especificadas e melhoria na operação. Caso os excessos sistêmicos, baseados no Iopc, não sejam eliminados as penalidades serão efetuadas, numa segunda etapa.

0 estudo demonstrou que investimentos em tecnologias para o setor de transportes permitem adotar políticas de inclusão ao transporte público e tornar o ônibus acessível às categorias até então excluídas, sem provocar alterações em seu nível de qualidade e sem desequilíbrios financeiros ao sistema. Assim, o transporte público pode ser condicionante básico da qualidade de vida das pessoas, e não apenas mais uma atividade econômica voltada exclusivamente ao lucro.

\section{Referências}

ANTP (2012) Sistemas Inteligentes de Transportes. Série Cadernos Técnicos, vol. 8, ANTP, Banco Mundial.

BHTRANS/Prefeitura de Belo Horizonte (2012) Gerência de Controle e Estudos Tarifários. Relatório gerencial, v. out/2012, Belo Horizonte.

Carvalho, C. H. R.de, Pereira, R. H. M., Vasconcellos, E. A., Galindo, E. P., \& Neto, V.C.de L. (2010) A mobilidade urbana no Brasil. In: Maria da Piedade Morais; Marco Aurélio Costa. (Org.). Infraestrutura Social e Urbana no Brasil: subsídios para uma agenda de pesquisa e formulação de políticas públicas. Brasília: Ipea, 2010, v. 2, p. 549-592.

Cham L.C. (2006) Understanding Bus Service Reliability: A Practical Framework Using AVL/APC Data (Master's thesis), Massachusetts Institute of Technology, Boston.

Couto, D.M. (2011) Regulação e Controle Operacional no Transporte Coletivo Urbano: Estudo de caso no município de Belo Horizonte/MG (Dissertação) Programa de Pós-Graduação em Geotecnia e Transportes da Escola de Engenharia da UFMG, Belo Horizonte, Brasil.

Cui, A. (2006) Bus Passenger Origin-Destination Matrix Estimation Using Automated Data Collection Systems (Doctoral dissertation), Massachusetts Institute of Technology, Boston.

Farzin, J.M. (2008) Constructing an Automated Bus Origin-Destination Matrix Using Farecard and Global Positioning System Data in São Paulo, Brazil. Transportation Research Record: Journal of the Transportation Research Board, Washington, n. 2072, p. 30-37. DOI: 10.3141/2072-04.

FJP - FUNDAÇÃO JOÃO PINHEIRO (2012) Pesquisa de emprego e desemprego na Região Metropolitana de Belo Horizonte (PED/RMBH): Belo Horizonte, novembro 2012. Disponível em: <http://www.fjp.gov.br>.

Guerra, A.L., Barbosa, H.M., \& Oliveira, L.K. (2014) Estimativa de matriz origem/destino utilizando dados do sistema de bilhetagem eletrônica: proposta metodológica. Transportes v. 22, n. 3, 2014. ISSN: 2237-1346 (online). DOI: 10.14295/transportes.v22i3.789.

IBGE - INSTITUTO BRASILEIRO DE GEOGRAFIA E ESTATÍSTICA (2011) Índices Econômicos 2011. Disponível em: $<$ http://www.ibge.gov.br>

Lathia, N.; Smith, C., Froehlich, J., \& Capra, L. (2013) Individuals among commuters: Building personalised transport information services from fare collection systems. Pervasive and Mobile Computing, Volume 9, p 643-664. http://dx.doi.org/10.1016/j.pmcj.2012.10.007

Ministério das Cidades (2004) Política nacional de mobilidade urbana sustentável. Secretaria Nacional de Transportes e da Mobilidade In: Cadernos Cidades Mobilidade Urbana. Brasília: Governo Federal.

Mojica, C.H. (2008) Examining Changes in Transit Passenger Travel Behavior through a Smart Card Activity Analysis (Master's thesis), Massachusetts Institute of Technology, Boston.

Nunes, N.T.R. (2010) Sistema de ônibus semiurbano: Uma maneira eficiente de redução de tarifas. Revista dos Transportes Públicos, ANTP.

Pires, F.L. (2008) Mobilidade Urbana e Princípios de Justiça. Letras Livres, Série Anis, Ano VIII, n.63, p.1-11.

Trépanier, M., Morency, C., \& Blanchette, C. (2008) Les systèmes de paiement par cartes à puces: un complément aux enquêtes originedestination? 43e Congrès de l'Association québécoise du transport et des routes, (AQTR), Ville de Québec, Canada, 14-16 avril 2008.

Vasconcellos E.A.de (2005) A cidade, o transporte e o trânsito. Prolivros, São Paulo.

Zhao, J. (2004) The Planning and Analysis Implications of Automated Data Collection System: Rail Transit OD Matrix Inference and Path Choice Modelling Examples (Doctoral dissertation), Massachusetts Institute of Technology, Boston.

\section{Abstract}

This study presents a method capable of monitoring and evaluating critical occupancy rates in urban public transportation considering route segments with the highest ridership demand. The objective is to detect periods of the day with lower occupancy rates than the maximum permitted by contract, in order to include beneficiaries without the need of paying full fares. The method was applied in a case study in Belo Horizonte city based on boarding and alighting surveys and on the treatment and statistical analysis of database from the Automatic Fare Collection system - AFC. A new indicator of comfort level was formulated, Index of Desirable Comfort, necessary to define the fleet idle capacity during operation and to quantify the beneficiaries with fare discounts during specific periods. Economical evaluation shows that over 100,000 beneficiaries could be included in the system during off-peak, approximately the total of unemployed in the city. The study demonstrated that investments in transportation technologies allow inclusion policies and make the bus accessible to excluded categories, without provoking changes to the quality level and financial disequilibrium to the system.

Key words: social fare, bus occupancy, public transportation. 